\title{
An Empirical Study of Online and Offline Price Deviation in B2C Market
}

\author{
Rongrong Fu \\ South China University of Technology, Guangzhou, China \\ Email:719022789@qq.com
}

How to cite this paper: Fu, R.R. (2019) An Empirical Study of Online and Offline Price Deviation in B2C Market. Open Journal of Business and Management, 7, 519-524. https://doi.org/10.4236/ojbm.2019.72035

Received: February 12, 2019

Accepted: March 19, 2019

Published: March 22, 2019

Copyright $\odot 2019$ by author(s) and Scientific Research Publishing Inc. This work is licensed under the Creative Commons Attribution International License (CC BY 4.0).

http://creativecommons.org/licenses/by/4.0/

\begin{abstract}
In this paper, we use Python crawler to automatically collect price information of online and offline electrical appliances on e-commerce websites, collect price information of offline electrical appliances market through field research, and compare and analyze commodity price and dispersion of online and offline electrical appliances market using market price dispersion model. The results show that although there is some price dispersion in the online market, the online household appliances market is still lower than the offline market, and the market efficiency is higher. Moreover, the discrete degree of online and offline prices has obvious "festival effect" in China's "Double Eleventh and Double Twelfth" online shopping festivals.
\end{abstract}

\section{Keywords}

Frictionless Market, Price Dispersion, Crawler, Statistical Analysis

\section{Introduction}

In the 1990s, some scholars put forward the theoretical hypothesis that e-commerce market will lead to "frictionless market"-The development of e-commerce will lead to the gradual disappearance of price dispersion among different retailers in the market: e-commerce market can effectively reduce search costs, improve information transmission efficiency and transparency, so as to enhance market efficiency [1]. However, many scholars have raised objections: through empirical research, it is found that market friction has not decreased with the development of e-commerce. Therefore, in the context of the rapid development of e-commerce and the unprecedented aggravation of the convergence of online and offline industries in China's e-commerce market, the empirical study of the "frictionless transaction hypothesis" and the analysis of the impact of e-commerce development on market efficiency can not only improve the theoretical basis of the dis- 
cipline in the field of e-commerce, but also have important significance for the development of domestic e-commerce. In this paper, we use data crawler program and statistical analysis method to analyze the problem from three aspects: theoretical basis, model construction and statistical analysis.

\section{Theoretical Background}

\subsection{Raise Question}

Stigler [1] put forward the theoretical explanation of price dispersion in 1961: because of incomplete information, the price distribution of homogeneous commodities (It can be either a product of the same brand type or a product with the same function) sold by different sellers is different at the same time in the same market. Salop et al. [2] argued that because of the high cost of collecting commodity prices, consumers would abandon purchasing goods at the lowest or lower prices. Burdett et al. [3] argued that the more information consumers have, the lower the cost of collection, the lower the market price dispersion. Bakos et al. [4] define that the greater the price dispersion of a market, the less information it has and the less efficient it is. Through the continuous improvement of some experts and scholars, the hypothesis of "Frictionless Transaction" has been formed: E-commerce will effectively reduce market prices and price dispersion. However, in recent years, empirical studies at home and abroad show that the price dispersion of online market has not been reduced because of the reduction of information search cost [5]-[10], which is contrary to the expectations of the theoretical circle.

\subsection{Selection of Standards}

According to the China E-Commerce Report [11] published in 2017, online business transactions have become an irreplaceable new force in Chinese consumer market. Statistics from the National Bureau of Statistics show that in 2017, e-commerce transactions in China reached 29.16 trillion yuan, an increase of $11.7 \%$ over the previous year, while online retail sales reached 7.18 trillion yuan, an increase of $32.2 \%$ over the previous year. By the end of 2017, the number of online shopping users in China had reached 533 million, an increase of $14.3 \%$ over the previous year. In 2017, e-commerce in China maintained a high-speed growth trend, with the largest online retail scale in the world.

Past literature shows that in recent years, the main research objects of this kind of empirical research are [12]: DC, DV, books, computer software, vitamin drugs, electronic products, sports and outdoor products, household appliances, automobiles, toys, office products, online travel market, online booking, rental, insurance and so on. The empirical results partly support the hypothesis and partly oppose it.

Based on previous studies, the author selected the most representative household electronic products as the research object. Considering the author's energy and convenience, the scope of data collection and research is set in Guangzhou, China. As a first-tier city in China, Guangzhou has a large number of e-commerce 
businesses, sufficient market inventory, fast price updates, and rich data resources. According to China E-Commerce Report [11], Guangzhou retail sales ranked first in the whole country for four consecutive years, with strong representativeness.

\subsection{Data Record}

After a comprehensive survey of the strength and data capacity of major e-commerce platforms. The author chooses four online e-commerce platforms, namely Jingdong, Suning, Tianmao(the official flagship store of Taobao) and Gome, to price the selected electrical appliances. In order to ensure data quality, the author tries to select official flagship stores and self-owned commodity data. Off-line data collection points are Gome Electrical Appliances in Victoria Square, Suning Electrical Appliances in Tianhe Road and Suning Electrical Appliances in Zhengjia Square (Suning and Guomei are the two largest offline shopping malls for household appliances in China), totally 3 stores in Tianhe District of Guangzhou City.

The author selected nine categories of electrical appliances (washing machines, refrigerators, air conditioners, mobile phones, TV, computers, kitchen appliances, toilet appliances, living appliances), a total of 90 kinds of household appliances. Data acquisition once a week. The observation time is from August 26, 2018 to December 16, 2018. We continuously observed 20 periods of online and offline data, collected 6988 sample values of online commodity prices and 6732 sample values of offline commodity prices, totaling 13,720 sample values.

\subsection{Data Processing}

The core part of this subject is data acquisition and collation. This paper needs a large number of accurate and scientific data with long time span to support the hypothesis, which makes the conclusions drawn in this paper more scientific and illustrative. In the past, the data acquisition methods of this kind of research are manual acquisition, with low efficiency and accuracy, and there are many household appliances, long data acquisition period and huge collection time cost. The author compiles Python program to meet the needs of data acquisition, and realizes the automatic collection of online data.

The target data is the online price of the same type of goods (a total of 90 goods) on four shopping websites. The author obtains the price data through the analysis of the commodity details page. The price loading mode of the target website is asynchronous loading, and the price data can't be obtained by the conventional data crawler. The author uses selenium (python-controlled tools for testing web applications) and chrome to implement price data crawler, and uses xlwt package to write the final result to excel file.

\section{Empirical Model}

\subsection{Discreteness Analysis}

The efficiency of e-commerce market can be examined from the perspectives of 
price level, price dispersion coefficient and price adjustment frequency. Following is a statistical analysis of the sample data collected by the above data collection methods to meet the requirements of comparability and integrity.

There are several indices to measure the dispersion: range, variance, standard deviation, coefficient of variation, fractional difference, coefficient of dispersion, etc. The coefficient of variation (the standard deviation of the same commodity price divided by the average price of the commodity) is selected as the index to measure the discrete situation. Specific price discretization is shown in Table 1.

1) Stigler [1] believes that the price dispersion of a highly efficient market should be between $5 \%$ and $10 \%$, and that when it exceeds $10 \%$, there is a large information asymmetry in the market. According to this standard, there is a large market information asymmetry in both online (10.47\%) and offline (18.42\%) electrical markets.

2) Overall, there is a certain gap between the online and offline price dispersion of all kinds of electrical appliances, and the offline price dispersion is greater than the online price dispersion. The overall difference was $7.94 \%$.

3) The difference of online and offline dispersion of different types of electrical commodities is different. Among them, the disparity between online and offline prices of computers is $11.45 \%$, while the disparity between online and offline prices of mobile phone (4.44\%), air conditioner $(5.00 \%)$ and TV $(7.60 \%)$ is relatively small.

\subsection{Non-Parameter Statistics: Wilcoxon Signed-Rank Test}

In order to test whether the difference in sales price between the two types of retailers is significant statistically, the author further tests the sample data with non-parametric tests that do not require too high sample size and distribution. The original hypothesis $\mathrm{H} 0$ is: there is no significant difference in the sales price between the two types of retailers. The alternative hypothesis $\mathrm{H} 1$ is that there is a significant difference in the selling price between the two types of retailers. In this paper, the test results of 20 sample data are shown in Table 2.

Table 1. On-line and off-line price for different types of household e-commerce products.

\begin{tabular}{cccccc}
\hline Category & Washing machine & TV & Mobile phone & Computer & Refrigerator \\
\hline Online average price & 4260 & 7265 & 3841 & 5552 & 5193 \\
Offline average price & 5832 & 9104 & 4207 & 8858 & 6994 \\
Online price dispersion coefficient (\%) & 11.18 & 10.82 & 4.56 & 8.46 & 12.93 \\
Offline price dispersion coefficient (\%) & 20.32 & 18.42 & 9.00 & 19.91 & 22.03 \\
\hline Category & Air conditioner & Kitchen appliances & Toilet appliances & Living appliances & Population \\
\hline Online average price & 5765 & 2925 & 782 & 1825 & 3517 \\
Offline average price & 6546 & 4176 & 1020 & 2927 & 4704 \\
Online price dispersion coefficient (\%) & 8.74 & 14.04 & 16.93 & 12.08 & 10.47 \\
Offline price dispersion coefficient (\%) & 13.74 & 22.40 & 25.11 & 21.33 & 18.42
\end{tabular}


Table 2. Wilcoxon test results of all online and offline products.

\begin{tabular}{ccccccccccc}
\hline Phase & $1^{\text {st }}$ & $2^{\text {nd }}$ & $3^{\text {rd }}$ & $4^{\text {th }}$ & $5^{\text {th }}$ & $6^{\text {th }}$ & $7^{\text {th }}$ & $8^{\text {th }}$ & $9^{\text {th }}$ & $10^{\text {th }}$ \\
\hline Z value & -2.135 & -1.067 & -0.077 & 0.845 & 1.137 & -0.314 & -1.766 & -0.309 & 2.118 & 0.972 \\
P value & 0.454 & 0.286 & 0.939 & 0.524 & 0.276 & 0.753 & $0.077^{* *}$ & 0.379 & $0.056^{* *}$ & 0.191 \\
phase & $11^{\text {th }}$ & $12^{\text {th }}$ & $13^{\text {th }}$ & $14^{\text {th }}$ & $15^{\text {th }}$ & $16^{\text {th }}$ & $17^{\text {th }}$ & $18^{\text {th }}$ & $19^{\text {th }}$ & $20^{\text {th }}$ \\
Z value & -1.503 & 1.177 & 2.010 & -1.004 & 1.521 & 0.003 & -0.235 & 1.033 & -2.482 & -5.05 \\
P value & 0.133 & 0.246 & $0.044^{*}$ & 0.334 & 0.136 & 0.998 & 0.814 & 0.321 & $0.013^{*}$ & 0.613 \\
\hline
\end{tabular}

*: There is a significant difference in the price between the two types of retailers at the $5 \%$ significant level. ${ }^{*}$ : There is a significant difference between the price of the two types of retailers at $10 \%$ significant level.

As can be seen from Table 2, most of the test results can't reject the original hypothesis, and there is no significant difference in online price dispersion. For all 90 types of merchandise, there is a significant difference between the prices of the $13^{\text {th }}$ (The $\mathrm{T}$ value is 0.044 ) and $19^{\text {th }}$ (The $\mathrm{T}$ value is 0.013 ) phases at the $5 \%$ significant level. There was a significant difference between the samples in the $7^{\text {th }}$ and $9^{\text {th }}$ phases at $10 \%$ significance level. It is noteworthy that there are obvious "festival effects" in $13^{\text {th }}$ (Chinese Double Eleven E-commerce Shopping Festival) and $19^{\text {th }}$ (Chinese Double Twelve E-commerce Shopping Festival) phases. From the $9^{\text {th }}$ phase (October $20^{\text {th }}$, the start date of Double Eleventh Shopping Festival), $\mathrm{P}$ value gradually decreased, to the $13^{\text {th }}$ issue rejected the original hypothesis at the $5 \%$ significance level, indicating that there was a significant difference between the prices of the two types of retailers. This result shows that as a large-scale e-commerce festival in China, the domestic e-commerce shopping festival "Double Eleven" and "Double Twelve" have a great impact on the price of household appliances market, resulting in the widening of the price gap between online and offline household appliances during the activity period.

\section{Conclusion}

To sum up, this paper collects the prices of online and offline electrical appliances by means of programming, field research and other methods. And statistical analysis of these price data to verify whether e-commerce can effectively reduce market friction. The results show that the price of online and offline electrical appliances market has a large degree of discreteness, but the market efficiency of online market is higher, and its price discreteness is less than offline discreteness, the final empirical conclusion supports the "frictionless hypothesis" (e-commerce reduces market dispersion). Moreover, there is obvious "festival effect" during the online shopping festival.

\section{Conflicts of Interest}

The author declares no conflicts of interest regarding the publication of this paper.

\section{References}

[1] Stigler, G. (1961) The Economic of Information. Journal of Political Economy, 69, 
213-225. https://doi.org/10.1086/258464

[2] Salop, S. and Stiglitz, J. (1982) The Theory of Sales: A Simple Model of Equilibrium Price Dispersion with Identical Agents. The American Economic Review, 72, 1121 2230.

[3] Burdett, K. and Coles, M. (1997) Steady State Price Distributions in a Noisy Search Equilibrium. Journal of Economic Theory, 72, 1-32. https://doi.org/10.1006/jeth.1996.2189

[4] Bakos, Y. (1997) Reducing Buyer Search Costs: Implications for Electronic Market places. Management Science, 43, 1676-1692.

https://doi.org/10.1287/mnsc.43.12.1676

[5] Bailey, J.P. (1998) Intermediation and Electronic Markets: Aggregation and Pricing in Internet Commerce. Doctoral Dissertation, Massachusetts Institute of Technology, Dept. of Electrical Engineering and Computer Science, Cambridge, 9-130.

[6] Bailey, J.P. (1998) Electrical Commerce: Prices and Consumer Issues for Three Products: Books, Compact Discs and Software. Working Paper OCDE/GD(98)4, Organization for Economic Co-Operation and Development, 3-51.

[7] Brynjolfsson, E. and Smith, M.D. (2000) Frictionless Commerce? A Comparison of Internet and Conventional Retailers. Management Science, 46, 563-585. https://doi.org/10.1287/mnsc.46.4.563.12061

[8] Clay, K., Krishnan, R., Wolff, E. and Fernandes, D. (2002) Retail Strategies on the Web: Price and Non-Price Competition in the Online Book Industry. The Journal of Industrial Economics, 50, 351-367. https://doi.org/10.1111/1467-6451.00181

[9] Lee, Z. and Gosain, S. (2002) A Longitudinal Price Comparison for Music CDs in Electronic Commerce. Journal of Business Strategies, 11, 63-88.

[10] Scholten, P. and Smith, S.A. (2002) Price Dispersion Then and Now: Evidence from Retail and E-Tail Markets. Advances in Microeconomics: Economics of the Internet and E-Commerce. Advances in Applied Microeconomics, 11, 63-88. https://doi.org/10.1016/S0278-0984(02)11028-5

[11] CNNIC (2018) 2017 Chinese E-Commerce Report.

[12] Zhang, R.C. (2016) Multi-Agent Based Simulation for the Price Dispersion in Online Markets. Hunan University, Changsha. 